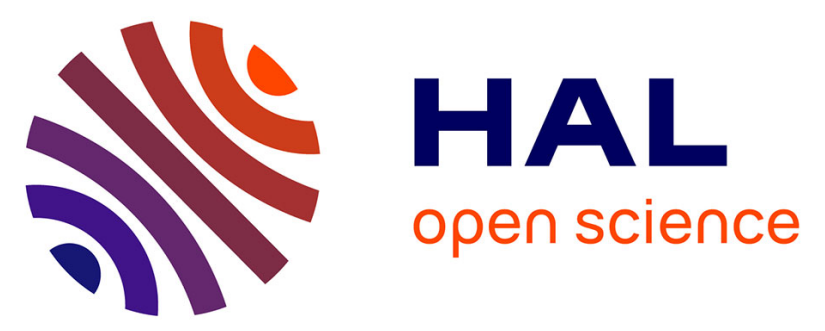

\title{
Flow and mixing efficiency characterisation in a CO2-assisted single-screw extrusion process by residence time distribution using Raman spectroscopy
} Audrey Common, Élisabeth Rodier, Martial Sauceau, Jacques Fages

\section{- To cite this version:}

Audrey Common, Élisabeth Rodier, Martial Sauceau, Jacques Fages. Flow and mixing efficiency characterisation in a CO2-assisted single-screw extrusion process by residence time distribution using Raman spectroscopy. Chemical Engineering Research and Design, 2014, 92 (7), p. 1210-1218. 10.1016/j.cherd.2013.10.013 . hal-01611624

\section{HAL Id: hal-01611624 \\ https://hal.science/hal-01611624}

Submitted on 13 Nov 2017

HAL is a multi-disciplinary open access archive for the deposit and dissemination of scientific research documents, whether they are published or not. The documents may come from teaching and research institutions in France or abroad, or from public or private research centers.
L'archive ouverte pluridisciplinaire HAL, est destinée au dépôt et à la diffusion de documents scientifiques de niveau recherche, publiés ou non, émanant des établissements d'enseignement et de recherche français ou étrangers, des laboratoires publics ou privés. 


\title{
Flow and mixing efficiency characterisation in a $\mathrm{CO}_{2}$-assisted single-screw extrusion process by residence time distribution using Raman spectroscopy
}

\author{
Audrey Common ${ }^{1}$, Elisabeth Rodier, Martial Sauceau, Jacques Fages* \\ Université de Toulouse, Ecole des Mines d'Albi, CNRS, RAPSODEE Centre, 81013 Albi, France
}

\begin{abstract}
A B S T R A C T
Hot-melt extrusion of a bio-sourced polyamide has been implemented in a single-screw extruder with supercritical carbon dioxide injection. $\mathrm{CO}_{2}$ acts as a plasticiser in the extruder barrel and as a physical blowing agent at the die. To insure a better mixing and dissolution of the $\mathrm{CO}_{2}$ into the polymer melt, addition of a static mixer between the screw tip and the die was tested. The effect of both the static mixing element and the $\mathrm{CO}_{2}$ injection on the melt flow behaviour has been elucidated. A recent technique of in-line Raman spectroscopy was implemented to make a residence time distribution study, using titanium dioxide as a tracer. The use of a static mixer exerts a major modification on the flow behaviour: it improves mixing by enhancing dispersion. In addition, the structure of the manufactured products was studied: the static mixer led to more homogeneous porous structure. The broad range of $\mathrm{CO}_{2}$ incorporation (up to $25 \%, \mathrm{w} / \mathrm{w}$ ) into the melt led to the manufacture of foams with adjustable porosity from 15 to $70 \%$.
\end{abstract}

Keywords: Hot-melt extrusion; Supercritical carbon dioxide; Residence time distribution; Static mixer; Raman spectroscopy

\section{Introduction}

Residence time distribution (RTD) measurement is a classic method used in chemical engineering. RTD function is a probability distribution function that monitors the time each fluid element spends inside a process operation. It has been used by chemical engineers in extrusion processes for more than 40 years to characterise and model the mixing and the flow within the extruder barrel (Pinto and Tadmor, 1970).

Single-screw extruders are widely used in several industries because of their simplicity and robustness. Processing polymers by hot-melt extrusion with such extruders is a common technique present in several industrial sectors. Although modern geometries have recently improved the mixing capacities of single-screw machines (Bi and Jiang, 2009; Wang et al., 2010) the poor mixing ability remains one of the major drawbacks of such process. Therefore, the study of the residence time distribution to better understand the flow behaviour in the extruder is a useful method which has been well documented (Seker, 2005).

The addition of static mixing elements just before the die is a common technique to ensure a better homogeneity of the melt entering the die. Thakur et al. (2003) have reviewed the use of such mixers in the process industries. Another technique to improve and enlarge the application of single-screw extrusion is the addition of supercritical carbon dioxide in the barrel to act as a removable plasticiser as well as a foaming agent (Mulvaney and Rizvi, 1993; Sauceau et al., 2011). This addition exerts also an influence on the global polymer flow (Singh and Rizvi, 1998; Nikitine et al., 2009).

In-line spectroscopic analysis is developing quickly mainly because it avoids tedious procedures of sampling and off-line

\footnotetext{
* Corresponding author at: Ecole des Mines d'Albi, Campus Jarlard, F-81013 Albi, France. Tel.: +33 563493 141; fax: +33563493025.

E-mail address: Jacques.Fages@mines-albi.fr (J. Fages).

${ }^{1}$ Present address: Feyecon, Inc. 1382 GS Weesp, The Netherlands.
} 
analyses (Barnes et al., 2007). A recent technique of RTD determination by Raman spectroscopy (Saerens et al., 2011) has been implemented.

This study deals with holt-melt extrusion of a polyamide polymer in a single-screw extruder. It aims at elucidating the influence of both the addition of a static mixer and supercritical $\mathrm{CO}_{2}$ injection on the melt flow behaviour. At first, a few theoretical concepts needed for the study of the distribution of residence times are given. The development of the RTD method is then detailed before presenting the experimental study describing (i) the effect of the operating parameters on the melt flow and (ii) the characterisation of the $\mathrm{CO}_{2}$-foamed polymer samples produced as a function of the addition of a static mixing element.

\section{Theory (Danckwerts, 1953; Villermaux, 1993)}

The function $E(t)$ is a normalised exit age distribution and is defined such that:

$\int_{0}^{\infty} E(t) d t=1$

$E(t) d t$ is the fraction of the fluid in the exit flow having a duration of $t$ inside the extruder. The cumulative and dimensionless curve $F(t)$ is defined by:

$$
\int_{0}^{t} E(t) d t=F(t)
$$

The average residence time $t_{\text {moy }}$ (equal to the first order raw moment $\mu_{1}$ ) is the average time spent by the fluid elements inside the extruder and is defined as the first moment of the function $E(t)$ :

$t_{\text {moy }}=\int_{0}^{\infty} t \cdot E(t) d t=\mu_{1}$

$t_{\text {moy }}$ can be compared to $\bar{t}$, the geometric residence time, i.e. the extruder volume filled with polymer, $\mathrm{V}$, divided by the volumetric flow rate $Q_{v}$.

$\bar{t}=\frac{V}{Q_{v}}$

Without any dead or stagnant zones, these two times are equal. $t_{\text {moy }}<\bar{t}$ may indicate the presence of a stagnant volume exchanging matter slowly with the main stream. This leads to a drag in the RTD curve. On the contrary $t_{\text {moy }}>\bar{t}$ is symptomatic of channelling or increased axial dispersion. Channelling may lead to the apparition of a small peak before the main stream peak.

The variance $\sigma^{2}$, the second order central moment of $E(t)$, gives the degree of dispersion around the mean and characterises the spreading of the RTD curve.

$\sigma^{2}=\int_{0}^{\infty}\left(\left(t-t_{\text {moy }}\right)^{2}\right) \cdot E(t) d t$
A dimensionless normalised variance $\operatorname{VarC}$ can be used to know whether or not, a parameter can modify the flow. It is defined as:

$\operatorname{VarC}=\frac{\sigma^{2}}{t_{m o y}^{2}}$

The onset time $t_{\text {app }}$ (at which the beginning of the peak is detected) can be useful in the ratio $t_{\text {app }} / t_{\text {moy }}$. It is equal to 1 for a plug flow and to 0 in a perfectly mixed reactor. It was evaluated to 0.75 for a single-screw extruder and 0.6 for a static mixer of Kenics type (Thakur et al., 2003).

Dimensionless parameters were defined as follows: (Ward et al., 1996).

$$
\begin{aligned}
t_{\text {adim }} & =\frac{t}{\bar{t}} \\
E_{\text {adim }} & =E(t) \cdot \bar{t}
\end{aligned}
$$

\section{Materials and methods}

\subsection{Extruder}

Hot-melt extrusion was performed using a single-screw Rheoscam extruder, which has a $30 \mathrm{~mm}$-screw diameter and a length to diameter ratio (L/D) of 35 (Scamex, France) already described in details elsewhere (Nikitine et al., 2010). Unless otherwise specified, extrusion temperature was $220^{\circ} \mathrm{C}$ and rotation speed of the screw was $40 \mathrm{rpm}$. Carbon dioxide, pumped from a cylinder by a syringe pump (260D, ISCO), is injected in the extruder barrel at a length to diameter ratio of 20 from the feed hopper at the same pressure as that of the extruder. The pump runs in a constant volumetric flow rate mode. The maximum $\mathrm{CO}_{2}$ flow rate is reached when destabilisation of the polymer flow occurs. The diameter of the cylindrical die is $2 \mathrm{~mm}$ and its length is $8 \mathrm{~mm}$. The static mixer used contains four elements with a diameter of $17 \mathrm{~mm}$ (SMB-H 17/4, Sulzer, Switzerland).

\subsection{Polymer}

Polyamide PA 11, commercial name Rilsan ${ }^{\circledR}$ (BMFO grade, Arkema, France), is a bio-sourced polymer amino-11undecanoic acid obtained from castor oil. It is a linear polymer with a number average molar mass of $8700 \mathrm{~g} \mathrm{~mol}^{-1}$ and a weight average molar mass of $20,010 \mathrm{~g} \mathrm{~mol}^{-1}$. In the following, it will be designated by PA.

\subsection{Tracer}

A Raman spectrometer (Kaiser Optical Systems, model $\mathrm{Rxn} 2^{\mathrm{TM}}$ cart version) equipped with an extruder immersion probe has been used to monitor in-line the tracer concentration in the melt. The probe was placed just before the die using a location initially devoted to a pressure gauge. The laser wavelength was $785 \mathrm{~nm}$, and the power was $400 \mathrm{~mW}$. Light was directed onto the polymer melt stream containing the tracer. The scattered light, which is different from the incident signal and whose wavelengths are characteristic of the sample, is monitored. We have chosen to perform pulse injections of tracer with a very small tracer mass compared to the total mass in the extruder. 


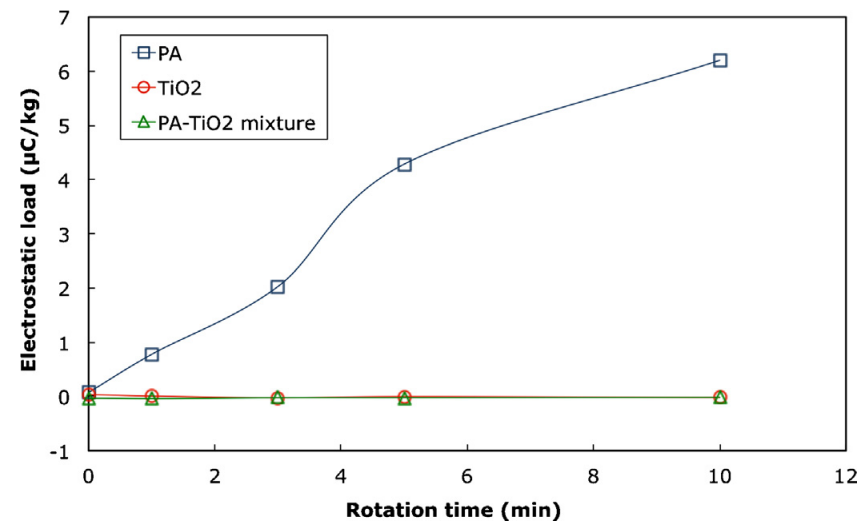

Fig. 1 - Electrostatic load of the materials versus rotation time.

\subsection{RTD determination}

Titanium oxide $\left(\mathrm{TiO}_{2}\right)$ in its anatase polymorph was chosen as a tracer and purchased from Riedel de Haën (Seelze, Germany). A small quantity of tracer, typically $0.5 \%, \mathrm{w} / \mathrm{w}$ is previously mixed with the polymer granules. The quality of the coating can be checked by the kinetics of triboelectrification of PA, $\mathrm{TiO}_{2}$ and a mixture of both components after being placed in a stainless steel rotative drum for $10 \mathrm{~min}$ (Fig. 1). The $\mathrm{TiO}_{2}$ powder being a good conductor coats the polymer granules which are insulating, as demonstrated by the low level of electrical charge of the mixture. Indeed, the electric potential of the mixture $(-340 \mathrm{~V})$ is much less than the potential measured with the polymer without tracer $(-1800 \mathrm{~V})$. Similarly, the relaxation time drops from more than $20 \mathrm{~min}$ (PA only) to $160 \mathrm{~ms}$ (mixture). In addition, $\mathrm{TiO}_{2}$ is a fine powder $\left(d_{50}=0.495 \mu \mathrm{m}\right)$ that can follow easily all the lines of flow within the extruder barrel. A previous study (Nikitine et al., 2009) had indeed revealed the importance of the fineness of the tracer, too large particles being subject to channelling. This method has allowed to use a simple physical mixture, without any other processing step.

A small quantity of mixture is then injected in the hopper onto the first screw thread and then covered with polymer. The signal was recorded over time with an exposure time of $5 \mathrm{~s}$ and spectrum acquisition was carried out every $10 \mathrm{~s}$. These two parameters were first tested. The exposure time was chosen to get a Raman spectrum whose intensity was high enough but not too noisy. The frequency of acquisition was chosen in order to get enough measurement points for the RTD function to be precise enough while being consistent with the exposure time. Raman spectra of pure $\mathrm{PA}$ and pure $\mathrm{TiO}_{2}$ are radically different, as shown in Fig. 2, the polymer peaks being obtained at high wavenumbers $\left(>1000 \mathrm{~cm}^{-1}\right)$ while the $\mathrm{TiO}_{2}$ peaks were observed at low wavenumbers $\left(<700 \mathrm{~cm}^{-1}\right)$. The maximum amount of $\mathrm{TiO}_{2}$ that can be introduced without disturbing the flow is however too small to give detectable peaks in the Raman signals. But the $\mathrm{TiO}_{2}$ being white, it absorbs significantly the main signal and reduces the intensity of the PA peaks according to its concentration. Fig. 3 shows the variation in the intensity of the main polymer peak as a function of time in the presence of tracer. This peak intensity was hence chosen for the RTD determination. This effect of lowering peak intensity was first observed by Vann et al. (2009) with nylon 6.6.

The tracer concentration $c_{m}(t)$ was deduced from the peak intensity $I(t)$ measured by the probe by assuming a direct proportionality and expressed in arbitrary units $(\mathrm{au})$ :

$c_{m}(t)=K^{\prime} \cdot\left(I_{P A}-I(t)\right)$

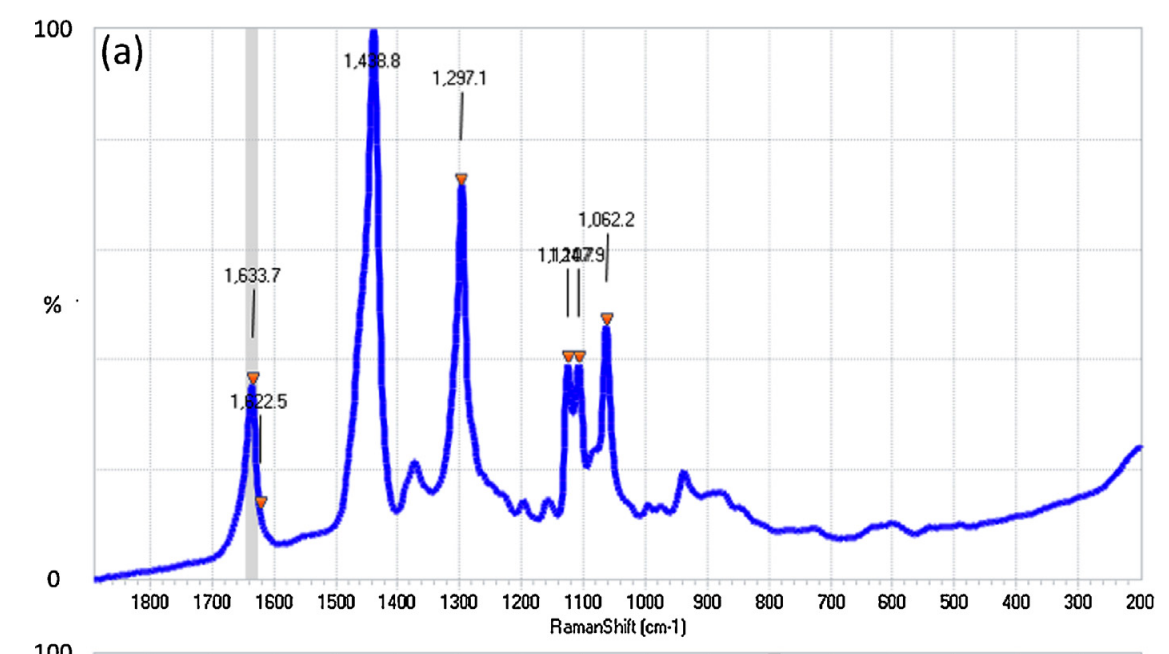

100 (b)

$\%$

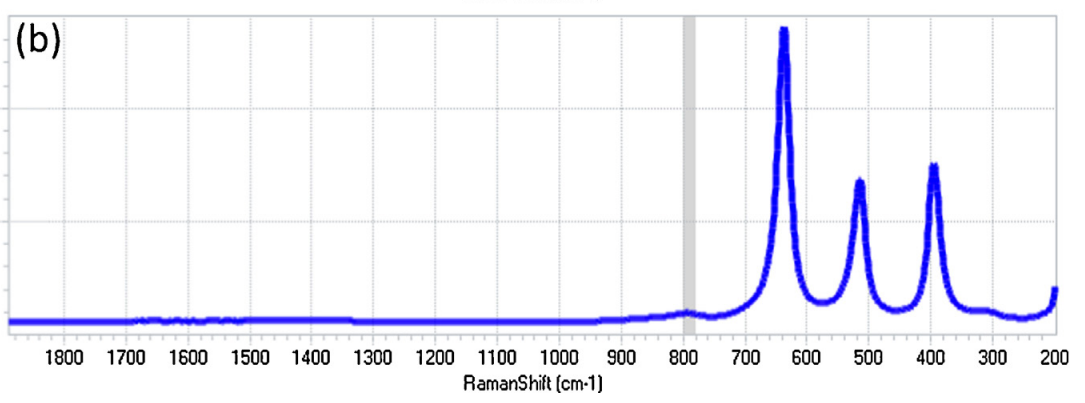

Fig. 2 - Raman spectra; (a) PA; (b) $\mathrm{TiO}_{2}$. 


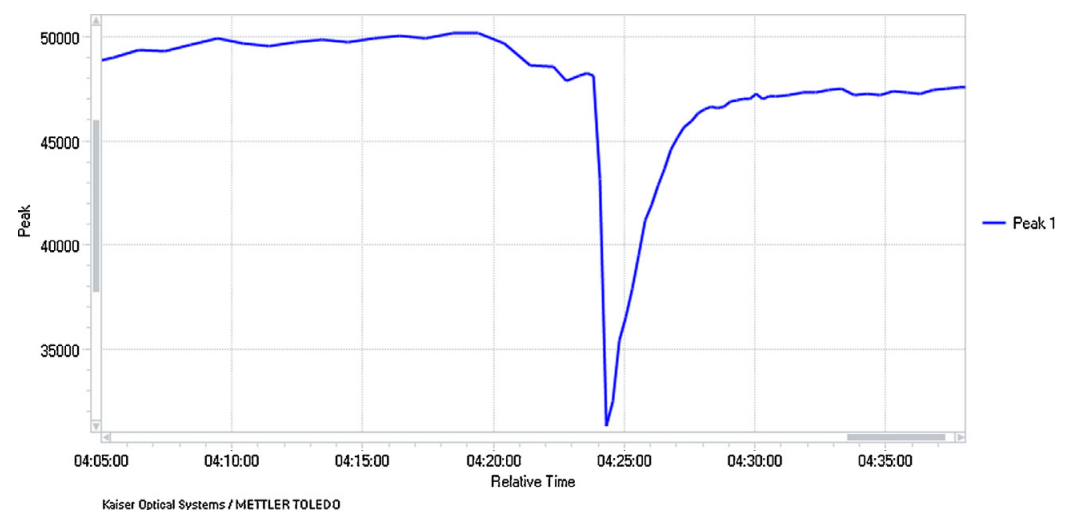

Fig. 3 - Main PA peak intensity in the presence of $\mathrm{TiO}_{2}$ as a function of time.

$I_{P A}$ is the intensity of pure PA signal (baseline) and $K^{\prime}$ is a constant characteristic of the polymer nature, once the exposure time is fixed. Consequently the RTD function $E(t)$ can be deduced from this signal by the following equation:

$E(t)=\frac{c_{m}(t)}{\int_{0}^{\infty} c_{m}(t) d t}=\frac{I_{P A}-I(t)}{\int_{0}^{\infty}\left(I_{P A}-I(t)\right) d t}$

In addition, the total mass of tracer $m_{\text {trac }}$ can be written as:

$m_{\text {trac }}=\int_{0}^{\infty} c_{m}(t) Q_{v} d t$

Therefore:

$m_{\text {trac }}=K^{\prime} Q_{v} S_{\text {pic }}$

where $S_{p i c}$ is the peak intensity surface and can be defined by:

$S_{\text {pic }}=\int_{0}^{\infty} I(t) d t$

\subsection{Sample characterisation}

Water and helium pycnometry (Micromeritics, AccuPYC 1330) were used to determine respectively, overall and closed porosity. The characterisation of the porosity structure was also studied by environmental scanning electron microscopy (ESEM, FEG, Philips).
Table 1 - Polymer and tracer masses used in experiments for the study of the pulse.

\begin{tabular}{lccc}
\hline Run \# & $\mathrm{mPA}(\mathrm{g})$ & $\mathrm{m} \mathrm{TiO}_{2}(\mathrm{mg})$ & \begin{tabular}{l}
$\mathrm{Mass} \mathrm{ratio}_{\mathrm{TiO}_{2} / \mathrm{PA}(\%)}$ \\
\hline 1
\end{tabular} \\
2 & 1.0551 & 27.7 & 2.63 \\
3 & 2.1536 & 93.7 & 4.35 \\
4 & 3.1616 & 173.9 & 5.50 \\
5 & 4.2607 & 188.3 & 4.42 \\
6 & 5.6771 & 178.8 & 3.15 \\
7 & 2.1124 & 113.0 & 5.35 \\
8 & 2.2821 & 58.2 & 2.55 \\
& 2.0349 & 22.6 & 1.11 \\
\hline
\end{tabular}

\section{Results and discussion}

4.1. Setting up the RTD measurement and validity of the results obtained

In addition to the frequency measurement and exposure time, two more parameters must be fixed: the width of the pulse, which is linked to the mass of the injected mixture, and the tracer concentration in the pulse.

4.1.1. Influence of the mass of the pulse

Table 1 gives the experimental conditions of 5 runs (1-5) done to elucidate the role of the total mass injected.

Screw speed, and thus flow rate, were kept constant in all 5 runs. The last two runs were however performed with another polymer batch, which induced a change in the intensity and

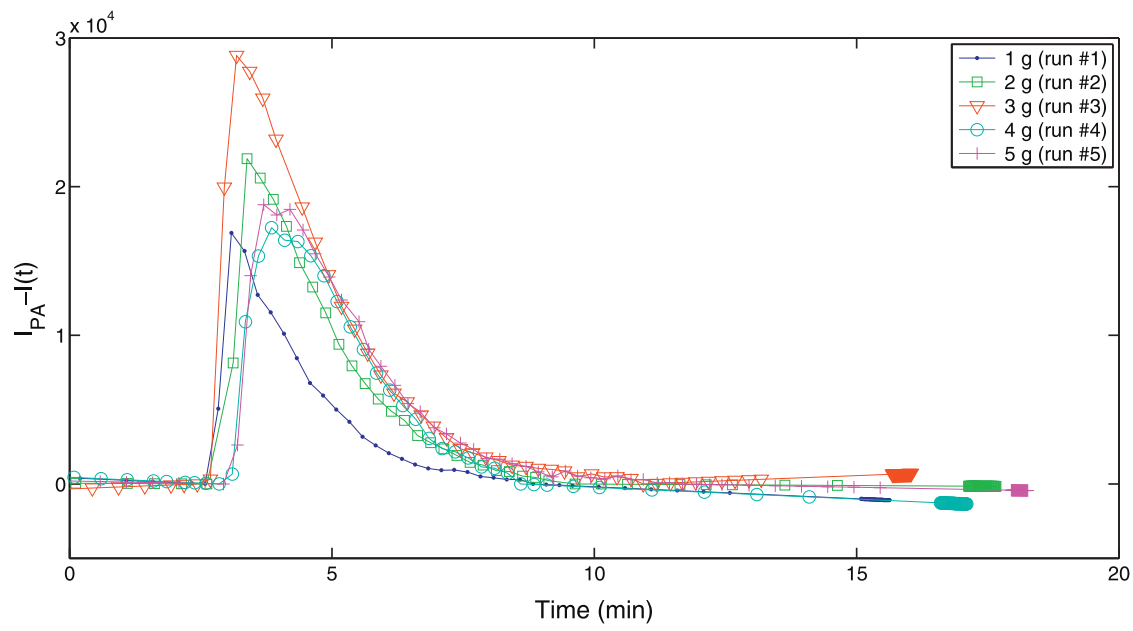

Fig. 4 - Time course of RTD curves for different pulse masses. 
Table 2 - Influence of pulse mass on RTD data.

\begin{tabular}{lcccccc} 
Run \# & $\mathrm{S}_{\text {pic }}\left(\mathrm{aus} \times 10^{4}\right)$ & $\overline{\mathrm{t}}(\mathrm{min})$ & $t_{\text {app }}(\mathrm{min})$ & $t_{\text {moy }}(\mathrm{min})$ & $\sigma^{2}\left(\mathrm{~min}^{2}\right)$ & $\mathrm{t}_{\text {app }} / \mathrm{t}_{\text {moy }}$ \\
\hline 1 & 2.96 & 3.9 & 2.6 & 4.2 & 4.3 & 0.074 \\
2 & 4.67 & 3.9 & 2.6 & 4.6 & 0.61 & 0.070 \\
3 & 6.81 & 3.9 & 2.4 & 4.8 & 2.1 & 0.57 \\
4 & 4.34 & 4.4 & 2.9 & 5.1 & 0.101 & 0.053 \\
5 & 4.96 & 4.2 & 2.9 & 0.59 & 0.078 \\
\hline
\end{tabular}

Table 3 - Influence of the tracer mass in the pulse on RTD data.

\begin{tabular}{lccccc} 
Run \# & $\mathrm{S}_{\text {pic }}\left(\mathrm{aus} \times 10^{4}\right)$ & $\overline{\mathrm{t}}(\mathrm{min})$ & $\mathrm{t}_{\text {app }}(\mathrm{min})$ & $\sigma^{2}\left(\mathrm{~min}^{2}\right)$ & $\mathrm{V}$ \\
\hline 6 & 2.59 & 3.9 & 2.6 & 1.3 & 0.069 \\
7 & 1.59 & 3.9 & 2.5 & 1.2 & 0.61 \\
8 & 0.81 & 3.9 & 2.6 & 0.8 & 0.62 \\
\hline
\end{tabular}

therefore in the peak area, but the shape of the RTD curves remained unchanged (Fig. 4).

Table 2 gives the values of the main parameters characterising the RTD. By comparing the first three experiments on one hand and the last two on the other hand, it is clear that the variance increases. Logically, the larger the impulse, the wider the peak. In addition, the normalised variance, which is characteristic of the flow type, is changed by increasing mass pulse, indicating a sensitivity of the RTD to this parameter probably due to the decrease of the quality of the pulse. A total mass of injected mixture of $2 \mathrm{~g}$ was therefore considered optimal to remain in pulse mode, while maintaining the intensity and thus the quality of the signal.

\subsubsection{Influence of the mass of $\mathrm{TiO}_{2}$ in the pulse}

In this section and in the following, the laser exposure time and the frequency acquisition time were reduced to respectively 5 and $10 \mathrm{~s}$ in order to increase the number of measurement points in the peak. The total injection mass being fixed at $2 \mathrm{~g}$, the influence of the percentage of $\mathrm{TiO}_{2}$ was studied (Table 1, runs 6-8). For a given flow rate and the same grade of the polymer, Fig. 5 shows a clear linear correlation between the peak area and the quantity of $\mathrm{TiO}_{2}$, thus validating the hypothesis made in Eq. (9).

Moreover, when the amount of $\mathrm{TiO}_{2}$ increases the signal intensity increases, and so does the peak width (i.e. the variance increases, see Table 3). However, the variation of the normalised variance seems to be limited. It can be thus considered that the output signal is slightly influenced by the tracer mass in the range studied. These three runs being done in very close experimental conditions giving similar RTD curves, they were used to evaluate the experimental error on $t_{\text {moy. }}$.

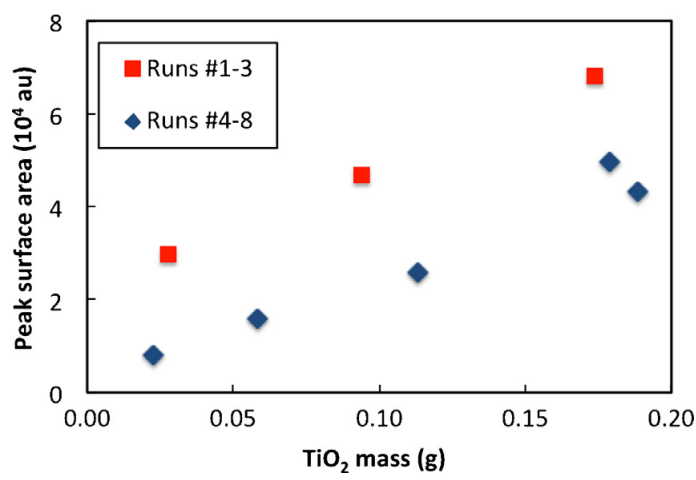

Fig. 5 - Peak surface as a function of $\mathrm{TiO}_{2}$ mass.
Table 4 - Experiments for the study of operating parameters.

\begin{tabular}{cccc} 
Run \# & Static mixer & $\mathrm{N}\left(\mathrm{min}^{-1}\right)$ & $\mathrm{CO}_{2}\left(\mathrm{ml} \mathrm{min}^{-1}\right)$ \\
\hline 9 & No & 30 & 0 \\
10 & No & 40 & 0 \\
11 & No & 60 & 0 \\
12 & No & 80 & 0 \\
13 & Yes & 40 & 0 \\
14 & Yes & 40 & 0 \\
15 & Yes & 40 & 0.7 \\
16 & Yes & 40 & 1.0 \\
\hline
\end{tabular}

The standard deviation of the three measurements was $17 \mathrm{~s}$ or $0.29 \mathrm{~min}$.

In conclusion to these experiments, it was decided to fix a $\mathrm{TiO}_{2}$ ratio of $2 \%$ on a total mass of $2 \mathrm{~g}$ (i.e. $40 \mathrm{mg}$ ) in all the following experiments. These figures appear to be the best compromise between the quality of the signal and the respect of a pulse mode.

\subsection{Influence of operating parameters on RTD}

\subsubsection{Screw speed}

Four experiments have been carried out at different screw speed (runs 9-12 in Table 4). First, we checked that the constant $K^{\prime}$ defined in Eq. (12), did not change with screw speed. Table 5 shows the values taken by $K^{\prime}$ as a function of the screw speed, which are always close to $\mathrm{K}^{\prime}=8 \cdot 10^{-8} \mathrm{~g} \mathrm{~cm}^{-3} \mathrm{au}^{-1}$.

The experimental results of RTD for runs 9-12 are given in Table 6 and illustrated in Fig. 6 . When the screw speed increases, the time of onset diminishes and so does the average residence time. This is a classic result already described in the literature (see for instance Bi and Jiang, 2009). In addition, the peak narrows with less drag, as demonstrated by the decrease of the variance. Table 6 shows differences between the geometric residence time and mean residence time, which are smaller or equal to the experimental error $(17 \mathrm{~s})$. The mean residence time is therefore not significantly greater than the geometric residence time.

In all experiments, the variance is of the same order of magnitude, indicating that the screw speed has no influence on the flow behaviour. This is confirmed by the very similar shape of

Table $5-K^{\prime}$ values as a function of screw speed.

\begin{tabular}{llccc} 
Run \# & 9 & 10 & 11 & 12 \\
$\mathrm{~K}^{\prime}\left(\mathrm{g} \mathrm{cm}^{-3} \mathrm{au}^{-1}\right) \times 10^{8}$ & 7.57 & 7.74 & 6.90 & 8.39 \\
\hline
\end{tabular}




\begin{tabular}{|c|c|c|c|c|c|c|c|}
\hline Run \# & $\bar{t}(\min )$ & $t_{a p p}(\min )$ & $t_{\text {moy }}(\min )$ & $\sigma^{2}\left(\min ^{2}\right)$ & VarC & $t-t_{\text {moy }}(\min )$ & $t_{\text {app }} / t_{\text {moy }}$ \\
\hline 9 & 5.3 & 3.4 & 5.5 & 1.9 & 0.064 & 0.2 & 0.63 \\
\hline 10 & 3.9 & 2.5 & 4.2 & 1.2 & 0.071 & 0.3 & 0.60 \\
\hline 11 & 2.4 & 1.6 & 2.7 & 0.5 & 0.066 & 0.2 & 0.59 \\
\hline 12 & 1.8 & 1.1 & 1.9 & 0.3 & 0.075 & 0.1 & 0.59 \\
\hline 13 & 4.86 & 3.02 & 6.36 & 3.68 & 0.091 & 1.70 & 0.47 \\
\hline 14 & 4.86 & 2.77 & 5.94 & 2.58 & 0.073 & 1.20 & 0.47 \\
\hline 15 & 6.20 & 3.97 & 7.78 & 5.28 & 0.087 & 1.78 & 0.51 \\
\hline 16 & 6.20 & 4.13 & 8.03 & 4.61 & 0.071 & 2.02 & 0.51 \\
\hline
\end{tabular}
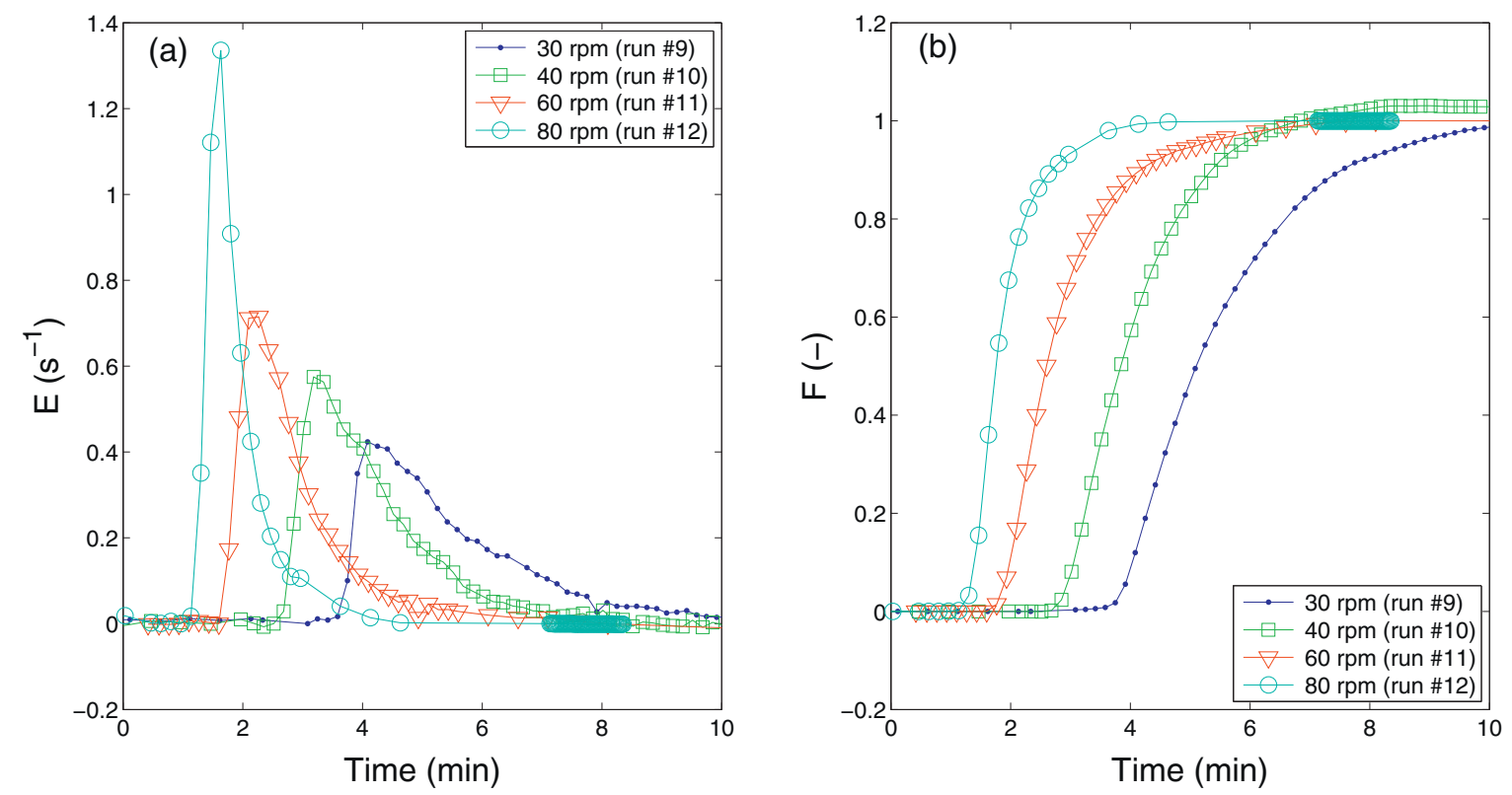

Fig. 6 - Influence of screw speed on RTD. Differential (a) and cumulative (b) curves.

dimensionless curves shown in Fig. 7. In addition, the ratio $t_{\text {app }} / t_{\text {moy }}$ hardly varies and remains close to 0.6 .

\subsubsection{Influence of the static mixer}

A static mixer element (Sulzer, SMR-H, 17/4) was added between the screw and the die to improve the mixing quality and thus minimising the plug flow effect (runs 13 and 14 in Table 4). As shown by the increase of the several characteristic times, the curves are shifted to higher times due to the increase of the free volume (runs 13 and 14 versus 10 in Table 6). The ratio $t_{\text {app }} / t_{\text {moy }}$ is much smaller in the presence of the mixer: 0.47 instead of 0.60 . This shows the evolution of the flow, evidencing a better mixing effect. In addition, the much larger difference $t_{\text {moy }}-\bar{t}$ could be explained by the increase of the distributive mixing, which then increases the residence time as explained in Section 2. Fig. 8 confirms that the mixer
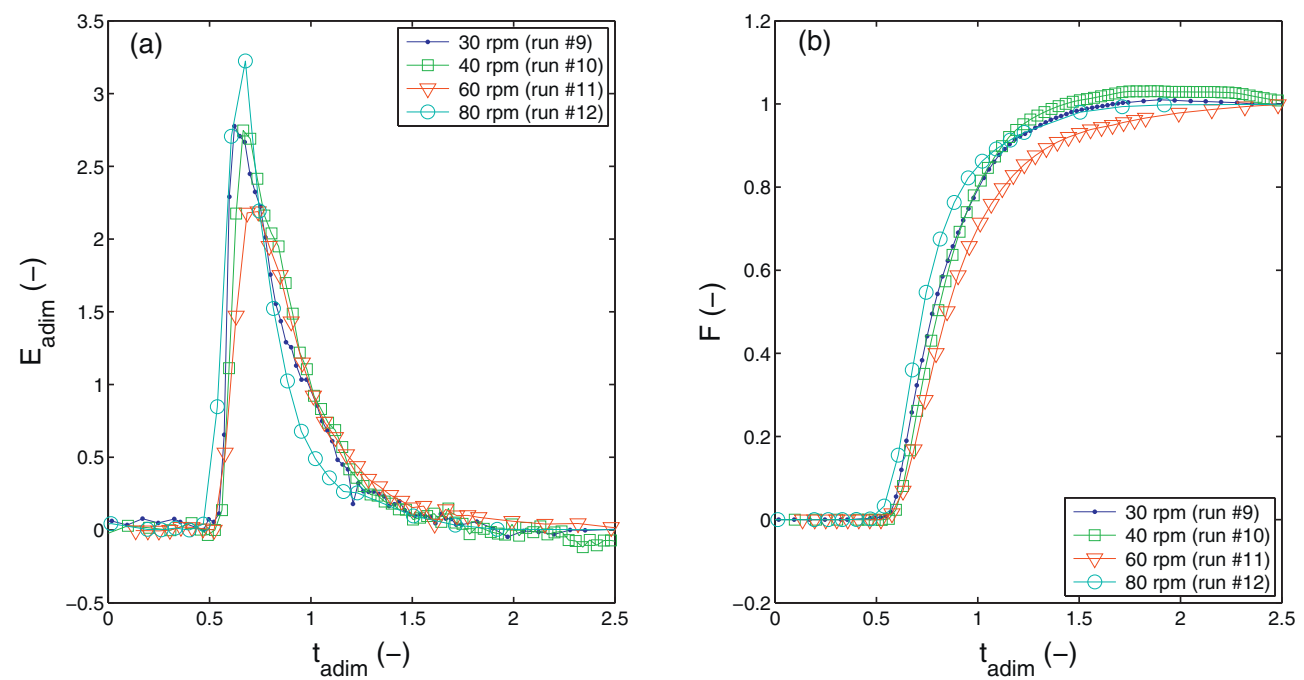

Fig. 7 - Influence of screw speed on dimensionless normalised RTD. Differential (a) and cumulative (b) curves. 

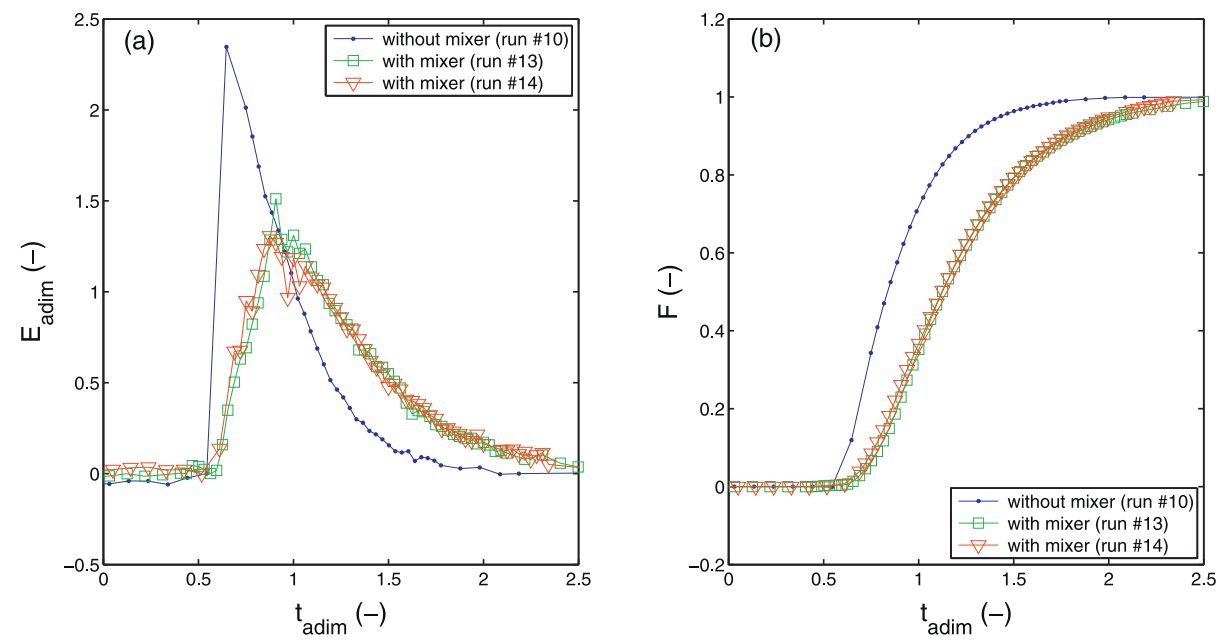

Fig. 8 - Influence of the presence of the static mixer on dimensionless normalised RTD. Differential (a) and cumulative (b) curves.

does change the flow. The dimensionless RTD curve broadens and exhibits a stronger drag and is closer to that of a stirred reactor.

\subsubsection{Influence of $\mathrm{CO}_{2}$ injection}

A study of $\mathrm{CO}_{2}$ injection on the melt flow in the presence of a static mixing element was also performed (runs 15 and 16 in Table 4). The addition of $\mathrm{CO}_{2}$ changes the throughput due probably to its plasticising effect (runs 15 and 16 versus 13 and 14 in Table 6). Indeed, the mean residence time as well as its standard deviation rose due to the mass-flow reduction. It is therefore necessary to use dimensionless time graphs for a proper comparison. Finally, it appears that $\mathrm{CO}_{2}$ injection does not affect the flow (Fig. 9).

\subsection{Characterisation of $\mathrm{CO}_{2}$-foamed samples}

4.3.1. Without static mixer

In this experiment, $\mathrm{CO}_{2}$ was introduced at $5 \mathrm{MPa}$. Fig. 10 shows that up to $7 \%$ of $\mathrm{CO}_{2}$ can be introduced while its solubility in PA has been measured using a magnetic suspension balance (data not shown) at 2.2\%. Below this limit, large pores can be observed while smaller pores with a more regular distribution appeared beyond the solubility limit. From this value and above, overall porosity decreases from $80 \%$ to $70 \%$, at the same time closed porosity increases from $25 \%$ to $60 \%$. At the highest $\mathrm{CO}_{2}$ ratio, most of the porosity is closed.

\subsubsection{With static mixer}

Using a static mixer enlarges dramatically the quantity of carbon dioxide, which can be introduced into the polymer melt as shown in Fig. 11. This addition favours $\mathrm{CO}_{2}$ incorporation through the increase in the pressure inside the barrel at which $\mathrm{CO}_{2}$ must be injected. In this experiment, the pressure was $12 \mathrm{MPa}$ corresponding to a $\mathrm{CO}_{2}$ solubility of $5.0 \%$. The highest $\mathrm{CO}_{2}$ mass ratio achieved was $27 \%$, more than 5 times the solubility.

Below the solubility, high porosity, with large inhomogeneous pores was observed. Homogeneous nucleation occurred (Park et al., 1995), followed by growth and coalescence of the pores during the temperature drop undergone by the samples after the die. For intermediate mass fractions of $\mathrm{CO}_{2}$, small and homogeneous pores in the centre surrounded by large pores near the sample circumference could be seen. At high $\mathrm{CO}_{2}$
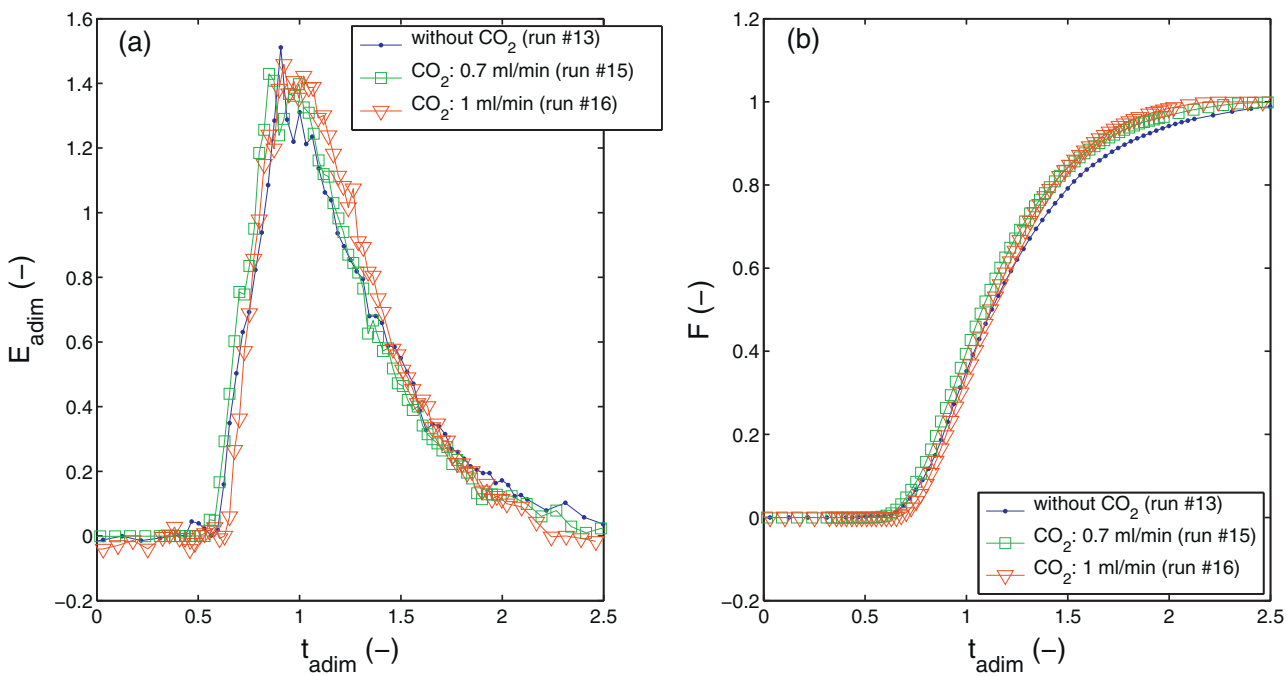

Fig. 9 - Influence of $\mathrm{CO}_{2}$ injection on dimensionless normalised RTD. Differential (a) and cumulative (b) curves. 


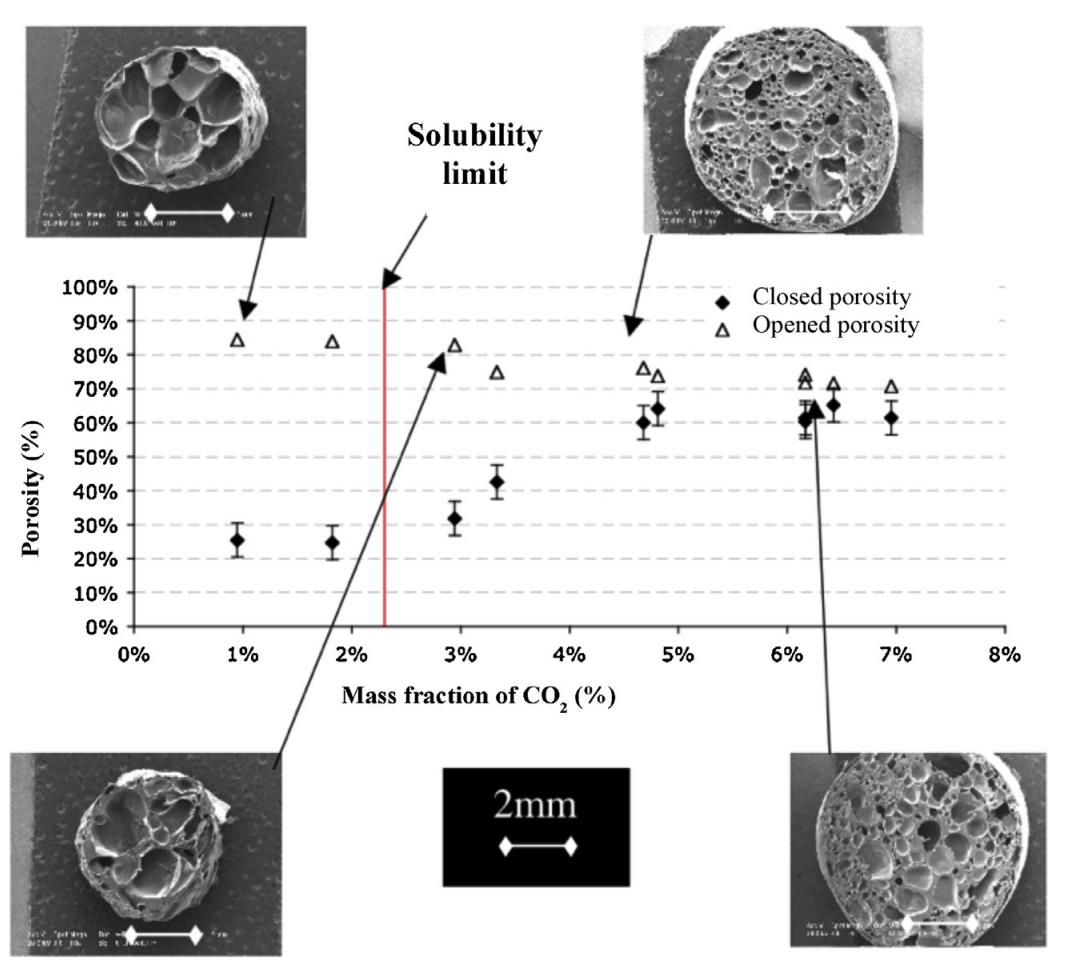

Fig. 10 - Global and closed porosity as a function of $\mathrm{CO}_{2}$ mass fraction.

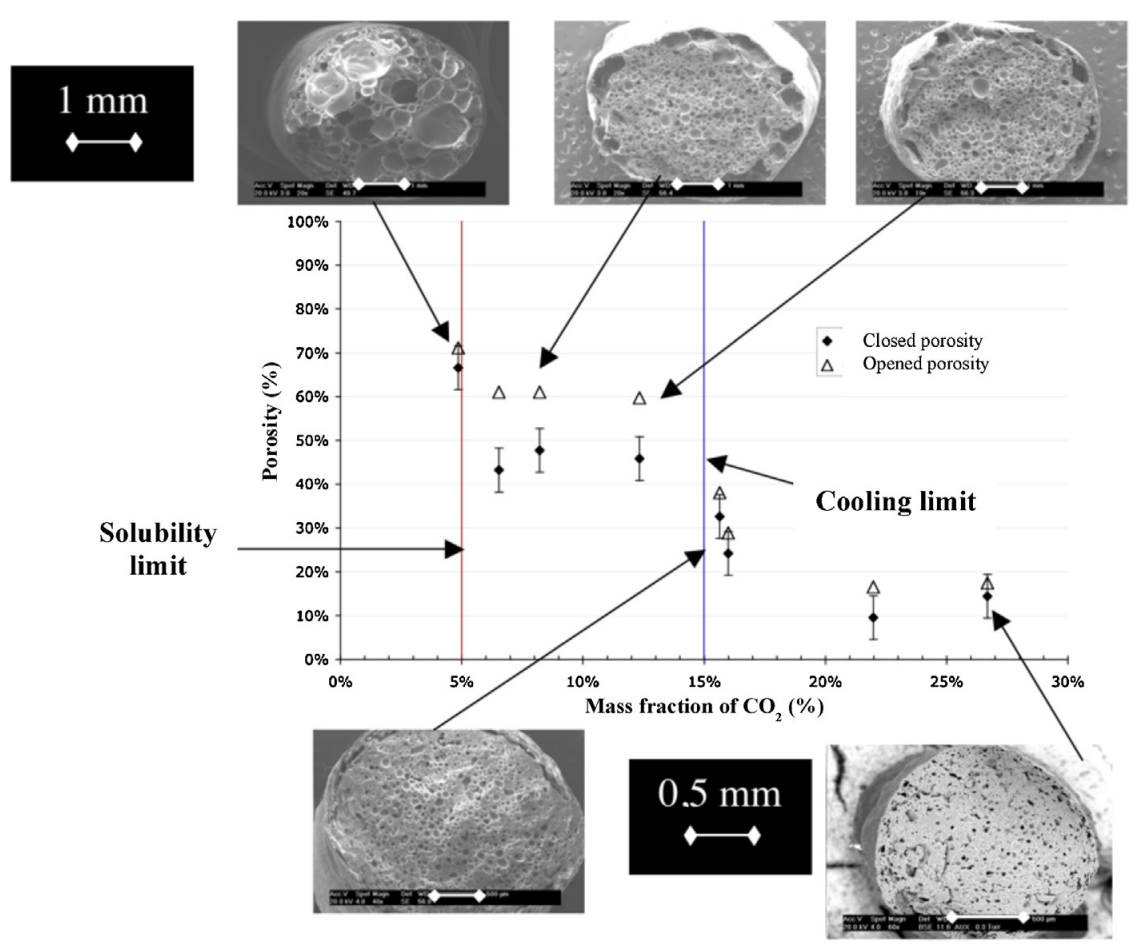

Fig. 11 - Global and closed porosity as a function of $\mathrm{CO}_{2}$ mass fraction in the presence of a static mixing element.

ratios, beyond $15 \%$, a severe drop in the global porosity was observed from $70 \%$ to less than $20 \%$. This was attributed to a strong cooling effect due to the depressurisation of large quantities of $\mathrm{CO}_{2}$, which prevents pores from growing and coalescing. This explains also why most of the porosity is closed, and a homogeneous appearance was obtained.

The use of a static mixer inserted between the screw tip and the die is therefore an efficient tool to get a homogeneous foamy structure. It allows a greater amount of $\mathrm{CO}_{2}$ to be injected in the extruder barrel, which controls the pore size and distribution.

\section{Conclusion}

Raman spectroscopy is a quick and efficient technique for the RTD determination in an extruder avoiding any sampling and subsequent analyses. The influence of different parameters on the flow behaviour has been elucidated. Nevertheless, the 
setting up and development phase can be tedious, especially for the Raman exposure time specification and the determination of the gap length between two measurements. The choice of a proper tracer to get a usable Raman response as well as the mode of injection are also crucial. We demonstrated that $\mathrm{TiO}_{2}$ can be a good tracer provided it is the attenuation of the polymer peak surface which is the chosen parameter to determine the RTD curves.

The use of a static mixer exerts a major modification on the flow behaviour: it improves mixing by enhancing dispersion. On the other hand, screw speed and compressed carbon dioxide addition play only a role on the throughput and mean residence time without disturbing the dispersion and leaving the flow behaviour unchanged. In addition, the use of a static mixer gives a more homogeneous foamy structure and allows the incorporation of much larger $\mathrm{CO}_{2}$ quantities in the polymer melt, up to $25 \%$ (w/w). Finally, the tuning of $\mathrm{CO}_{2}$ injection allowed the control of the porosity within a range of $15-70 \%$.

To go further, a flow modelling, with and without static mixer, appears necessary. Several modelling strategy using Markov chains (Ponomarev et al., 2012) or classic chemical engineering reactor modelling (Nikitine et al., 2009) could be used.

\section{Acknowledgements}

Authors gratefully acknowledge the Arkema company for providing the polymer and the financial support of the ANR (French national agency for research).

\section{References}

Barnes, S.E., Sibley, M.G., Edwards, H.G.M., Coates, P.D., 2007. Process monitoring of polymer melts using in-line spectroscopy. Trans. Inst. Meas. Control 29 (5), 453-465.

Bi, C., Jiang, B., 2009. Study of residence time distribution in a reciprocating single-screw pin-barrel extruder. J. Mater. Process. Technol. 209, 4147-4153.

Danckwerts, P.V., 1953. Continuous flow systems. Distribution of residence times. Chem. Eng. Sci. 2 (1), 1-13.

Mulvaney, S.J., Rizvi, S.S.H., 1993. Extrusion processing with supercritical fluids. Food Technol. 47 (12), 74-82.

Nikitine, C., Rodier, E., Sauceau, M., Fages, J., 2009. Residence time distribution of a pharmaceutical grade polymer/supercritical
$\mathrm{CO}_{2}$ melt in a single screw extrusion process. Chem. Eng. Res. Des. 87 (6), 809-816.

Nikitine, C., Rodier, E., Sauceau, M., Letourneau, J.-J., Fages, J., 2010. Controlling the structure of a porous polymer by coupling supercritical $\mathrm{CO}_{2}$ and single screw extrusion process. J. Appl. Polym. Sci. 115, 981-990.

Park, C.B., Baldwin, D.F., Suh, N.P., 1995. Effect of the pressure drop rate on cell nucleation in continuous processing of microcellular polymers. Polym. Eng. Sci. 35 (5), 432-440.

Pinto, G., Tadmor, Z., 1970. Mixing and residence time distribution in melt screw extruders. Polym. Eng. Sci. 10, 279-288.

Ponomarev, D., Nikitine, C., Sauceau, M., Rodier, E., Mizonov, V., Fages, J., 2012. Modelling non-homogeneous flow and residence time distribution in a single-screw extruder by means of Markov chains. J. Math. Chem. 50 (8), 2141-2154.

Saerens, L., Dierickx, L., Lenain, B., Vervaet, C., Remon, J.P., De Beer, T., 2011. Raman spectroscopy for the in-line polymer-drug quantification and solid state characterization during a pharmaceutical hot-melt extrusion process. Eur. J. Pharm. Biopharm. 77, 158-163.

Sauceau, M., Fages, J., Common, A., Nikitine, C., Rodier, E., 2011. New challenges in polymer foaming: a review of extrusion processes assisted by supercritical carbon dioxide. Prog. Polym. Sci. 36, 749-766.

Seker, M., 2005. Residence time distributions of starch with high moisture content in a single-screw extruder. J. Food Eng. 67, 317-324.

Singh, B., Rizvi, S.S.H., 1998. Residence time distribution (RTD) and goodness of mixing (GM) during $\mathrm{CO}_{2}$-injection in twin-screw extrusion - Part I: RTD studies. J. Food Process Eng. 21 (2), 91-110

Thakur, R., Vial, C., Nigam, K., Nauman, E., Djelveh, G., 2003. Static mixers in the process industries - a review. Chem. Eng. Res. Des. 81 (7), 787-826.

Vann, B.C., Angel, S.M., Hendrix, J.E., Bartick, E.G., Morgan, S.L., 2009. Analysis of titanium dioxide in synthetic fibers using Raman microspectroscopy. Appl. Spectrosc. 63 (4), 407-411.

Villermaux, J., 1993. Génie de la Réaction Chimique: Conception et Fonctionnement des Réacteurs, 2nd ed. Lavoisier, Tec et Doc, Paris.

Wang, C., Bussmann, M., Park, C.B., 2010. Numerical investigation of the effect of screw geometry on the mixing of a viscous polymer melt. J. Appl. Polym. Sci. 117 (2), 775-784.

Ward, N., Edwards, H., Johnson, A., Fleming, D., Coates, P., 1996. Application of Raman spectroscopy for determining residence time distributions in extruder reactors. Appl. Spectrosc. 50 (6), 812-815. 